\title{
MORPHOLOGY AND SYMMETRY OF THE VEGETATIVE PARTS OF SMILAX AURICULATA (SMILACACEAE)
}

\author{
George J. Wilder \\ Naples Botanical Garden \\ 4820 Bayshore Drive \\ Naples, Florida 34112-7336, U.S.A. \\ gwilder@naplesgarden.org
}

\begin{abstract}
Smilax auriculata produces a subterranean rhizome system and an aerial vegetative branching system. Three intergrading types of stems (types $\underline{1}, \underline{2}$, and $\underline{3}$ ) compose the aerial branching system; these types are identified primarily according to prickle concentration, but also differ from one another in additional ways. Type- $\underline{3}$ stems are determinate and either proleptic or precocious. Between growing seasons a foliage leaf of a type- $\underline{3}$ stem may subtend either a solitary vegetative bud (or an expanded vegetative branch) or an inflorescence superposed over a vegetative bud (or expanded vegetative branch). Occasionally, an inflorescence terminates a type- $\underline{3}$ stem. Whereas, rhizomes exhibit solely scale leaves, the aerial vegetative branching system manifests scale leaves, transitional leaves, and foliage leaves. On many type- $\underline{3}$ stems the foliage leaves become oriented skyward, by bending of their leaf sheaths and petioles. The aerial vegetative branching system manifests bilateral symmetry and mirror-image symmetry. The inflorescence is a pedunculate umbel. The peduncle culminates in a torus which bears a peripheral whorl of bracts, centripetally situated bracteoles, and pedicellate flowers. Type- $\underline{1}$ stems exhibit numerous prickles, which vary from unbranched to branched and from solitary to basally connate in rows.
\end{abstract}

\section{RESUMEN}

Smilax auriculata produce un sistema de rizomas subterráneos y un sistema aéreo de ramificación vegetativo. El sistema de ramificación aéreo está compuesto por tipos de tallos intergradados (tipos $\underline{1}, \underline{2}$, y ); estos tipos se identifican primariamente según su concentración de espinas, pero también difieren unos de otros de modo adicional. Los tallos Tipo- $\underline{3}$ son determinados y tanto prolépticos o precoces. Entre estaciones de crecimiento una hoja de un tallo tipo- $\underline{3}$ puede que subtienda tanto una yema vegetativa solitaria (o una rama vegetativa expandida) o una inflorescencia superpuesta a una yema vegetativa (o rama vegetativa expandida). Ocasionalmente, una inflorescencia termina un tallo tipo-3. Mientras, los rizomas tiene únicamente hojas escamosas, el sistema aéreo de ramificación vegetativa muestra hojas escamosas, hojas de transición, y hojas del follaje (nomófilos) . En muchos tallos tipo- $\underline{3}$ las hojas se orientan hacia el cielo, por curvatura de sus vainas y peciolos. El sistema aéreo de ramificación vegetativa muestra simetría bilateral y simetría en espejo. La inflorescencia es una umbela pedunculada. El pedúnculo culmina en un toro que lleva un verticilo periférico de brácteas, bractéolas situadas centrípetamente, y flores pediceladas. Los tallos tipo- $\underline{1}$ muestran numerosas espinas, que varían entre simples y ramificadas y de solitarias a en hileras connatas basalmente.

\section{INTRODUCTION}

Described herein are the gross morphology, symmetry, and selected developmental aspects of all organs of Smilax auriculata Walter, exclusive of floral organs and fruits.

This investigation was undertaken to develop a thorough, broadly focused morphological understanding of this species. Morphological aspects of S. auriculata had been considered in earlier floristic and taxonomic accounts of Smilax as a whole, but the descriptions were brief and sometimes mutually contradictory (Bullard \& Allen 2013; Clewell 1985; Coker 1944; Correll \& Correll 1982; Duncan 1975; Godfrey 1988; Godfrey \& Wooten 1979; Holmes 2002; Judd 1998; Long \& Lakela 1971; Morong 1894; Nelson 1996; Proenza \& Andreu 2013; Radford et al. 1968; Small 1933). As well, Caponetti and Quimby (1956), Fisher and French (1976), and Yates and Duncan (1970) had provided anatomical, but not morphological, accounts of this species.

Smilax auriculata, first described by Walter (1788), is a woody vine of the Smilacaceae. Its range encompasses seven contiguous coastal states within the southeastern United States, as well as Arkansas and the Bahamas. Florida is approximately central among those coastal states, and the species inhabits all 67 Florida counties (Bullard \& Allen 2013; Holmes 2002; Wunderlin et al. 2019). Smilax auriculata grows in deep, sandy 
soils and is common in disturbed sites, scrub, and coastal dunes, and less common in marshes, savannahs, and flatwoods (Proenza \& Andreu 2013).

The genus Smilax includes ca. 350 species which occur, collectively, "worldwide in the tropics and subtropics, with extensions into temperate areas" (Holmes 2002). Holmes (2002) indicated 20 species from North America north of Mexico. Qi et al. (2013) provided a recent phylogenetic assessment of the genus.

\section{METHODS AND TERMINOLOGY}

A single, extensive clump of $S$. auriculata was investigated. It grew within the Holmes Avenue Tract, a natural area managed by the Florida Fish and Wildlife Conservation Commission and located east of the town of Lake Placid (Highlands Co, Florida). The clump was discovered during a previous floristic inventory of the Tract, undertaken by Wilder et al. (2019).

The clump was visited repeatedly from/including Oct. 23, 2018 through May 15, 2019. Mostly, living material was studied, but certain specimens were dried or preserved in an aqueous glycerin-ethanol solution, prior to study. Also, dried voucher specimens were prepared and were deposited in the Herbarium of Southwestern Florida (SWF), i.e., Wilder \& McCombs 41594, 41595, 41596, 41597, 41705, 41739, 41819, and 42267.

On March 7, 2019, markers (pieces of yarn) were tied around the bases of intact, elongating, aerial stems. The markers served to identify the stems and, thereby, to trace their development later.

Present measurements are of living material, except where specified otherwise. Too, the measurements of stem diameters do not include stem-borne prickles. Median values for measurements are signified by $\tilde{\mathbf{x}}$.

For descriptive purposes I apply a concept of standard orientation to stems/stem sectors. In that orientation a stem or stem sector is positioned horizontally; it has that stem surface directed upward that was uppermost in nature; and it has its distal end positioned in front of, and pointed directly ahead of, the observer.

\section{RESULTS AND DISCUSSION}

The clump of S. auriculata was pistillate and grew within an insolated, disturbed portion of pine flatwoods (Fig. 2). It had an irregular, albeit, approximately elliptical perimeter and manifested major and minor diameters of $23 \mathrm{~m}$ and $14 \mathrm{~m}$, respectively. Most of the clump measured up to $3 \mathrm{~m}$ tall and occurred away from large trees and shrubs; however, a small portion, thereof, bordered a tree of Pinus elliottii ca. $13 \mathrm{~m}$ tall. There branches from the clump extended to the top of the tree.

\section{Rhizome system}

Contiguous rhizomes with axillary branching compose a subterranean rhizome system. The observed rhizomes were elongated, rather than tuberous, and were conspicuously swollen at the nodes (Figs. 3-5).

Rhizome diameters vary from ca. 1 to $5 \mathrm{~cm}$ (as measured at the nodes). The internodes range from 4.3 to $13.2 \mathrm{~cm}$ long $(\tilde{\mathrm{x}}=7.7 \mathrm{~cm} ; \mathrm{n}=15)$. The rhizomes generally grow parallel to, and within $15 \mathrm{~cm}$ of, the ground surface. They are generally cream-colored, but sometimes light brown, and bear comparably colored prickles (Fig. 4). The prickles range up to $4 \mathrm{~mm}$ long; they arise from the nodes and internodes, but in general are most numerous on the internodes. The rhizomes are glabrous (as are all others of the vegetative organs presently studied).

The prophyll (first-formed leaf) of a daughter rhizome is a scale leaf which occupies the typical prophyllar position for monocotyledons, i.e., the median of its abaxial surface faces the parent stem of the stem (rhizome in this case) which bears it. Subsequently formed leaves of the rhizome are also scale leaves (Fig. 5).

The scale leaves formed after the prophyll manifest alternate phyllotaxy (as do all leaves of the clump of $S$. auriculata presently studied; Figs. 4, 5). They are thin, more-or-less deltoid, and are appressed to the rhizome. They vary from reddish (when young) to brown or black. The well-developed ones measure 3.5 to $4.5 \mathrm{~cm}$ long. Basally, the margins of a scale leaf either overlap slightly, are slightly fused together, or terminate separately without overlap or fusion. Where the margins end separately their separation may be minimal or up to $1.4 \mathrm{~cm}$ (as measured along the longitudinal axis of the parent rhizome).

Some axillary buds of a rhizome may expand into daughter rhizomes. Also, some of the buds elongate 


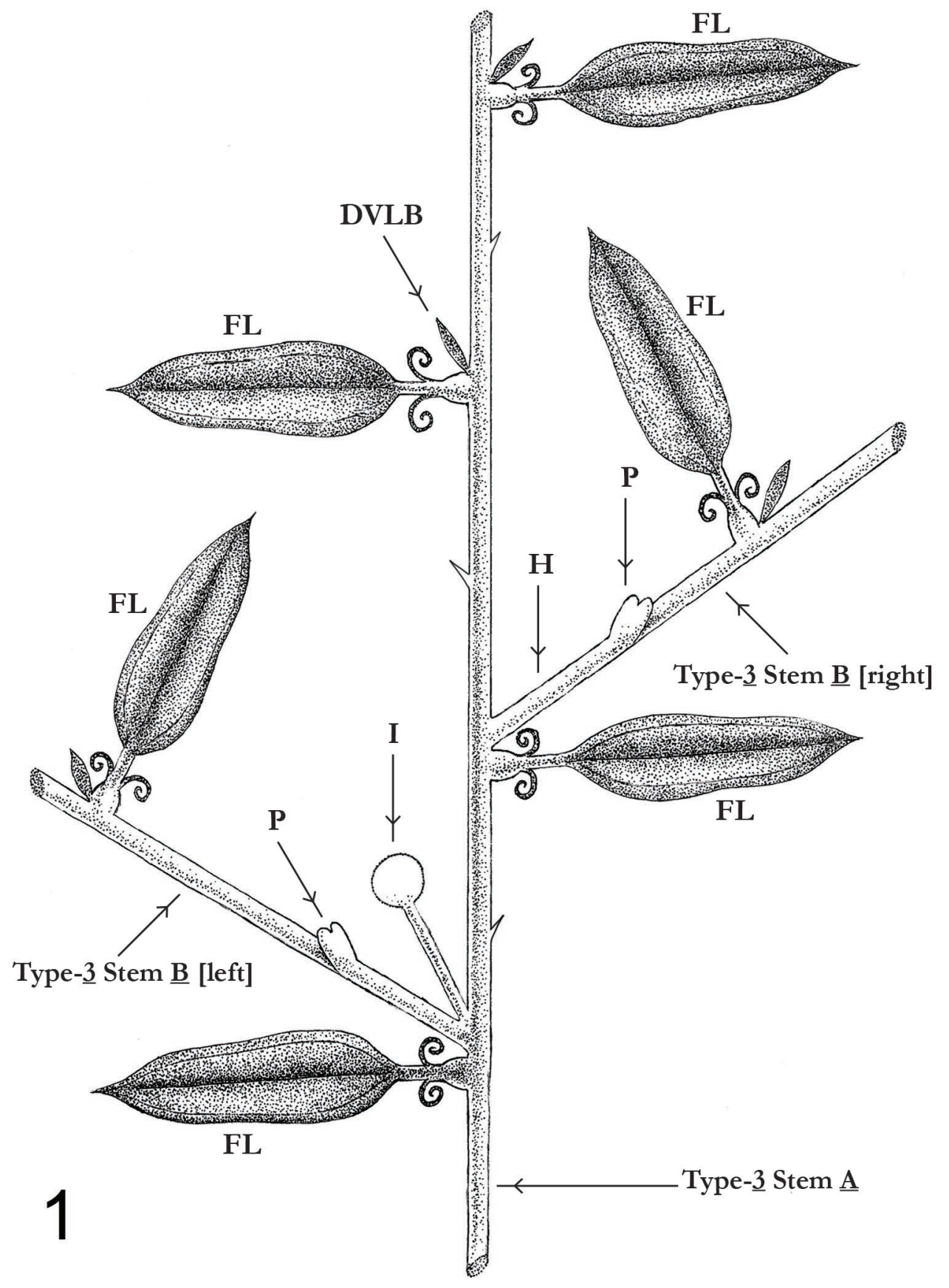

FIG. 1. Schematic diagram of a part of the aerial branching system of Smilax auriculata. All stems are viewed from above, and Type- $\underline{3}$ Stem $\underline{A}$ is illustrated in the standard orientation (defined in the text). For illustrative purposes, certain structures, e.g., the hypopodia, are drawn out of proportion. DVLB. Dormant vegetative lateral bud; FL. Foliage leaf; for each foliage leaf illustrated the leaf sheath and petiole are shown to be discrete and separated by two tendrils; H. Hypopodium. I. Inflorescence; only the globose torus and the subjacent, linear peduncle are represented; P. Prophyll; Type- $\underline{3}$ Stem A. A portion of a type- $\underline{3}$ stem; Type- $\underline{3}$ Stem $\underline{B}$ [left]. A portion of a type- $\underline{3}$ stem subtended by a foliage leaf of the left orthostiche of type- $\underline{3}$ stem $\underline{A} ;$ Type- $\underline{3}$ Stem $\underline{B}$ [right]. A portion of a type- $\underline{3}$ stem subtended by a foliage leaf of the right orthostiche of type- $\underline{3}$ stem $\underline{A}$. Drawing by Kristen Camisa. 


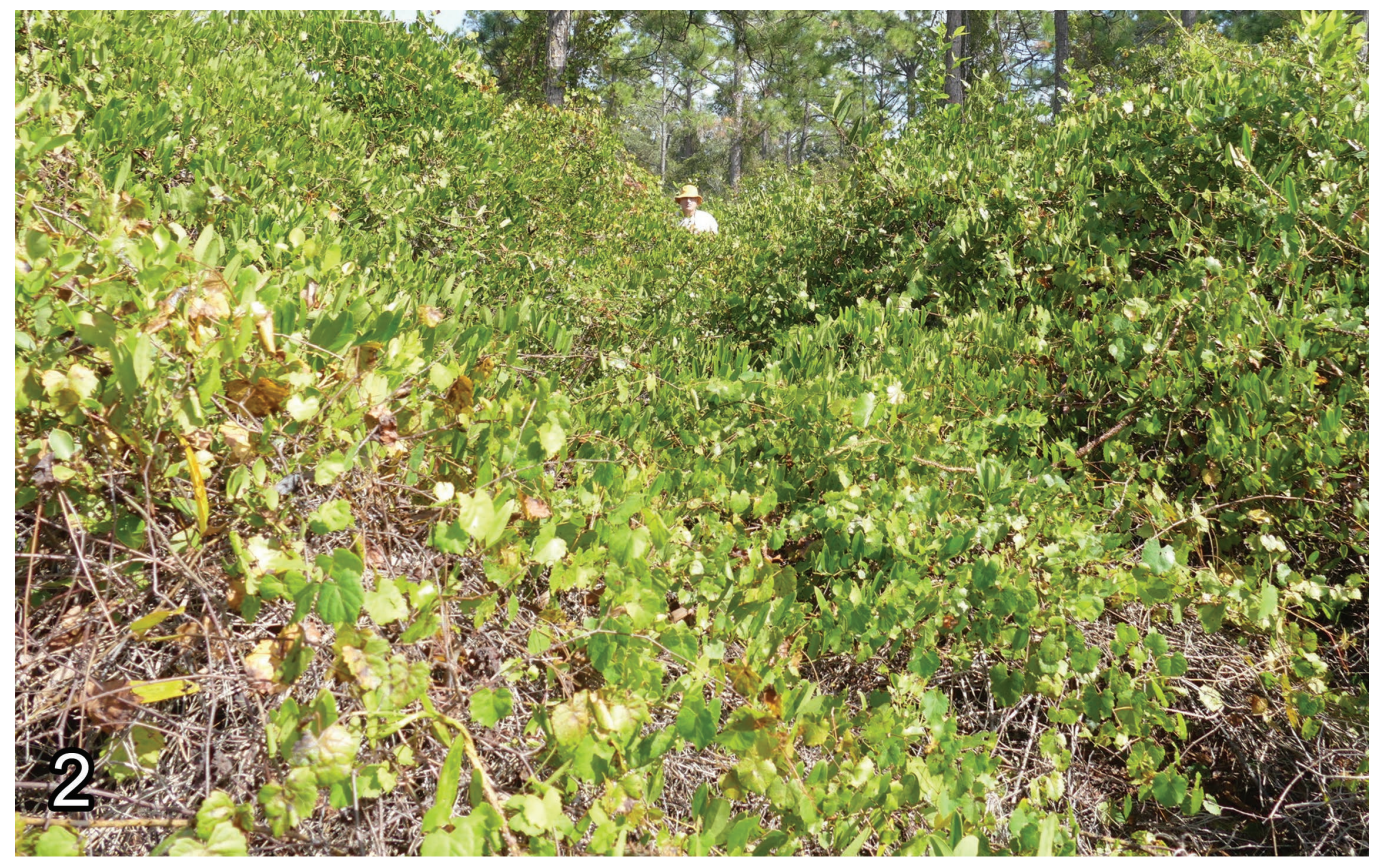

FIG. 2. Smilax auriculata. A portion of the clump, thereof, described in this paper. Vitis rotundifolia is prominent in the lower-left quadrant of this image. Photographic image by Jean McCollom.

minimally, apparently become dormant, and then appear as low, broad domes. A parent rhizome may bear such domes between the levels of insertion on the rhizome, of two expanded, successively formed daughter rhizomes situated some nodes apart.

The base of a daughter rhizome clasps its parent rhizome (Fig. 3, middle of figure). On a parent rhizome which bears two successively formed, expanded daughter rhizomes, the levels of insertion of the daughter rhizomes upon the parent rhizome range from 5 to $53 \mathrm{~cm}$ apart ( $\tilde{x}=8.3 \mathrm{~cm} ; \mathrm{n}=6$ measurements).

At least sometimes, a rhizome exhibits extra-vaginal branching, i.e., an elongating daughter rhizome induces splitting of, and grows through, its subtending scale leaf.

Comparison with previous accounts.-The present description of rhizomes, apparently, represents only part of the variation among underground stems of S. auriculata. Previous workers, collectively, reported "rhizomes," "tubers," and "non-stoloniferous, woody segmented rootstocks" (Coker 1944; Godfrey \& Wooten 1979; Holmes 2002; Judd 1998; Long \& Lakela 1971). Contrary to present findings, Coker (1944) reported "well defined potato-like tubers in chains and clusters or in heavier, more complicated masses ..." Holmes (2002) indicated "linear" rhizomes or "dense masses of potato-like tubers." Godfrey and Wooten (1979) reported "tuberous thickened rhizomes [arranged] in knobby chains or sometimes in knobby masses ..." Contrary to current findings for rhizomes, Coker (1944) characterized the "tubers" as "devoid of spines" (i.e., prickles).

Growth to the ground surface.-A rhizome may grow upward to the ground surface. There ensues a transformation in apical growth which yields a type-1, above-ground vegetative stem as a continuation of the rhizome (see below; Fig. 6). Compared to the rhizome, the type- $\underline{1}$ stem exhibits lesser diameter, different surficial color (see below), and in general a higher concentration of, and a greater maximum size of, prickles.

Because rhizomes branch and culminate in type- $\underline{1}$ aerial stems, the rate of horizontal expansion of the above-ground vegetative branching system is, apparently, positively correlated with that of the rhizome system. 


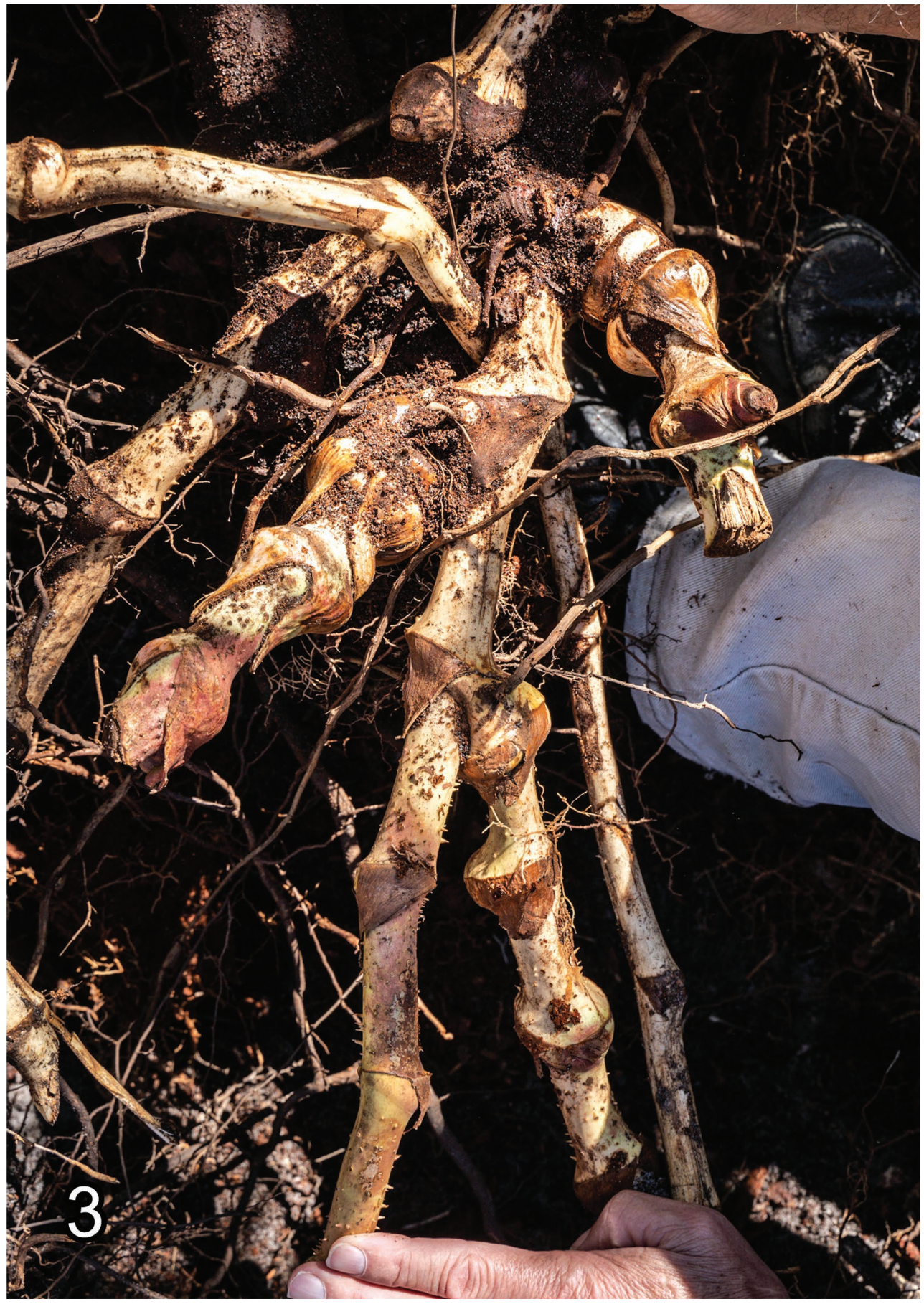

FIG. 3. Smilax auriculata. A portion of the rhizome system. Photographic image by Mary Dominguez. 


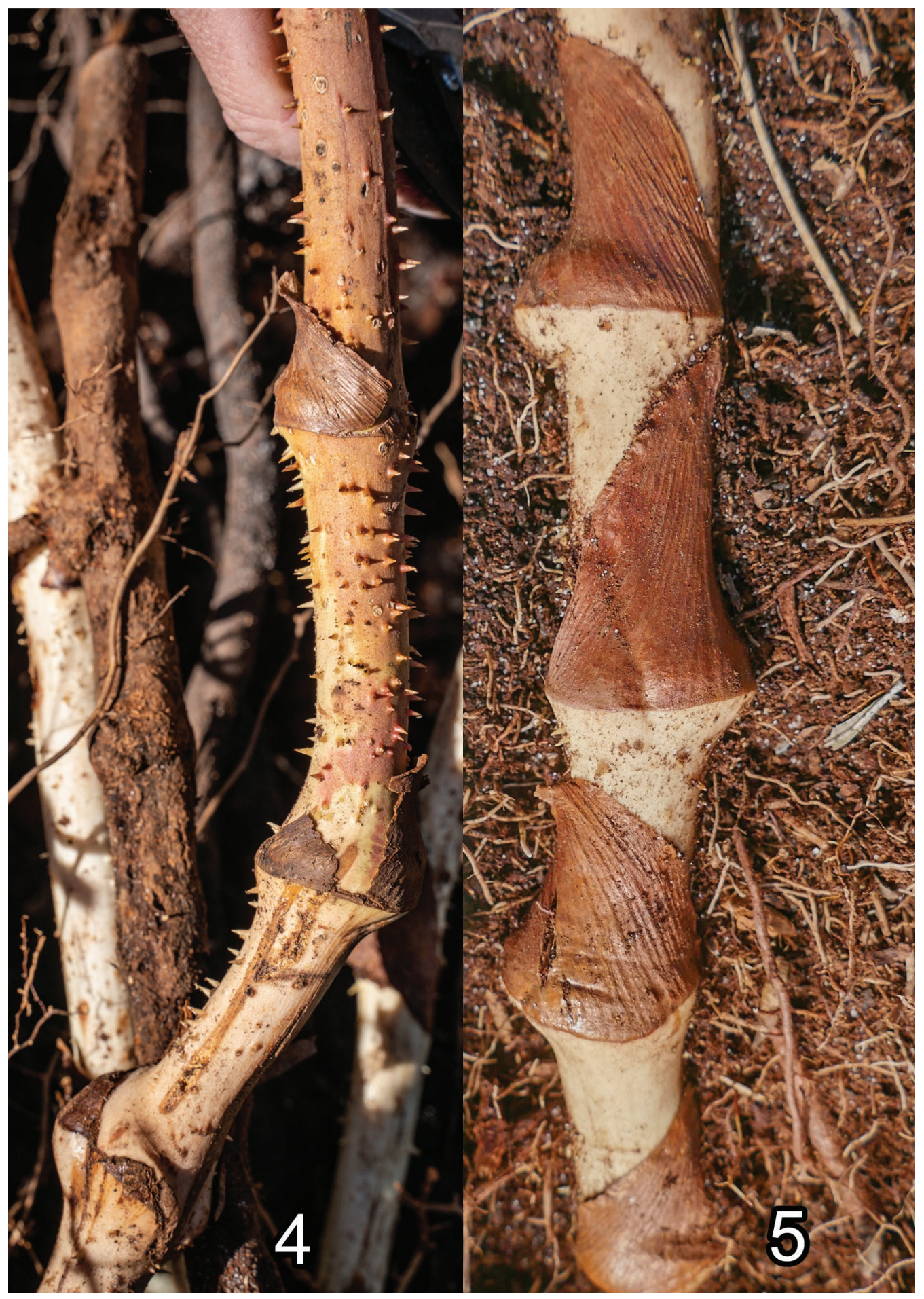

FIG. 4. Smilax auriculata. A portion of rhizome manifesting conspicuous prickles. Photographic image by Mary Dominguez. FIG. 5. Smilax auriculata. A portion of a rhizome with intact scale leaves. Photographic image by Jean McCollom. 


\section{Above-ground vegetative branching system}

Herein, I classify the stems, thereof, in two ways: $\mathbf{a}$. as types $\underline{1}, \underline{2}$, and $\underline{3}$, and $\mathbf{b}$. according to their orders of branching. Mostly, I utilize the first mode of classification, because often during field work the stem-prickles interfered with the tracing of, and the identification of, orders of branching.

The three types of stems intergrade with one another and are recognized based on differences in the concentrations of their prickles. As well, prickle concentrations correlate positively with, but not absolutely with, the lengths and widths of the stems.

Type-1 stems.-These are uncommon. They are unusual because they often exhibit very densely arranged prickles (Figs. 7, 8), because they are minimally branched, and because they have particularly long internodes (the two longest internodes measured were 23 and $25 \mathrm{~cm}$ long). Type- $\underline{1}$ stems recently emergent from the ground vary from erect to obliquely oriented (Fig. 6); however, without support from adjacent vegetation the longer stems may collapse under their own weight. Some long, mature stems were prostrate on the ground for much of their length. One might call the prostrate stem portions rhizomes, but they differ morphologically from the subterranean rhizomes.

Type- $\underline{1}$ stems are characteristically long and thick, and they elongate rapidly during their first growing season. One stem in its first season (which was still elongating when measured) was $3.2 \mathrm{~m}$ long. Five additional examples were measured. Three were damaged and lacked their distal portions; the remaining parts of the stems measured 3.5, 3.2, and $2.2 \mathrm{~m}$ long. A fourth stem graded distally into a type- $\underline{2}$ stem; the sector of the fourth stem which had type-1 morphology was $5 \mathrm{~m}$ long. The fifth stem, which bore a terminal bud, was $2.3 \mathrm{~m}$ long. All five stems were $13 \mathrm{~mm}$ thick; however, type- $\underline{1}$ stems overall ranged from 5 to $13 \mathrm{~mm}$ thick.

Two type-1 stems were observed which had had their distal ends amputated (apparently, by herbivore[s]). On each stem one or two vegetative axes had begun to expand basal to the severed portion.

A young type- $\underline{1}$ stem recently emergent from the ground appears pink, red, or purplish in surface view (Fig. 6). The foliage leaves of type- $\underline{1}$ stems are evergreen, as are all other foliage leaves of the above-ground branching system (Figs. 11, 12). Distally, a type- $\underline{1}$ stem may grade into a type- $\underline{2}$ stem. Too, by axillary branching a type- $\underline{1}$ stem may yield another type- $\underline{1}$ stem or a type- $\underline{2}$ stem.

Type-2 stems.-These manifest intermediate density of prickles and intermediate thickness (measuring 3.7 to $10 \mathrm{~mm}$ thick [ $\tilde{\mathrm{x}}=5.8 \mathrm{~mm} ; \mathrm{n}=10]$ ). Distally, a type- $\underline{\underline{2}}$ stem may grade into a type- $\underline{3}$ stem. As well, by axillary branching a type- $\underline{2}$ stem may yield another type- $\underline{2}$ stem or a type- $\underline{3}$ stem.

Type- $\underline{3}$ stems.-These exhibit sparsely arranged, and in places no, prickles (Figs. 9, 10, 13). The stems range from 3.5 to $126 \mathrm{~cm}$ long $(\tilde{x}=16 \mathrm{~cm} ; \mathrm{n}=25)$. They are narrow (measuring $1.2 \mathrm{~mm}$ to $3 \mathrm{~mm}$ thick $[\tilde{x}=1.6$ $\mathrm{mm} ; \mathrm{n}=10]$ ). By lateral branching a type- $\underline{3}$ stem may yield one or more additional type- $\underline{3}$ stems.

Types $\underline{1}$ to $\underline{3}$ stems differ in additional ways, indicated below.

Comparison with previous accounts. - Previous workers recognized that S. auriculata produces different kinds of aerial stems, but discussed them briefly and applied different terminology. Coker (1944), Nelson (1996), and Proenza and Andreu (2013) spoke of "canes" (probably type- $\underline{1}$ stems in some cases), of "leader shoots" and "lower stems," and of "lower stems of main shoots," respectively.

The type- $\underline{1}$ stems currently studied, apparently, manifested atypically many prickles for S. auriculata. Indeed, previous workers had characterized the prickles of this species as "scattered" (Nelson 1996; Proenza \& Andreu 2013), as "scattered [or] commonly wanting on the branches" (Morong 1894), as "sometimes" present (Small 1933), as "few" or absent (Correll \& Correll 1982), as "usually" absent (Radford et al. 1968), and as "sparingly" present (Long \& Lakela 1971). Holmes (2002), however, described them more comprehensively as "... numerous, sparse or absent distally." Also, the previous descriptions suggest that earlier workers mostly examined the (prickle-poor) type-3 stems (which predominate among herbarium specimens), rather than the (prickle-rich) type- $\underline{1}$ and type- $\underline{2}$ stems.

For S. auriculata, previous investigators understated the maximum diameters of the aerial stems as rarely over 5 to $8 \mathrm{~mm}$ (Coker 1944), as 5 to $8 \mathrm{~mm}$ (Holmes 2002), and as $9 \mathrm{~mm}$ (Bullard \& Allen 2013). 


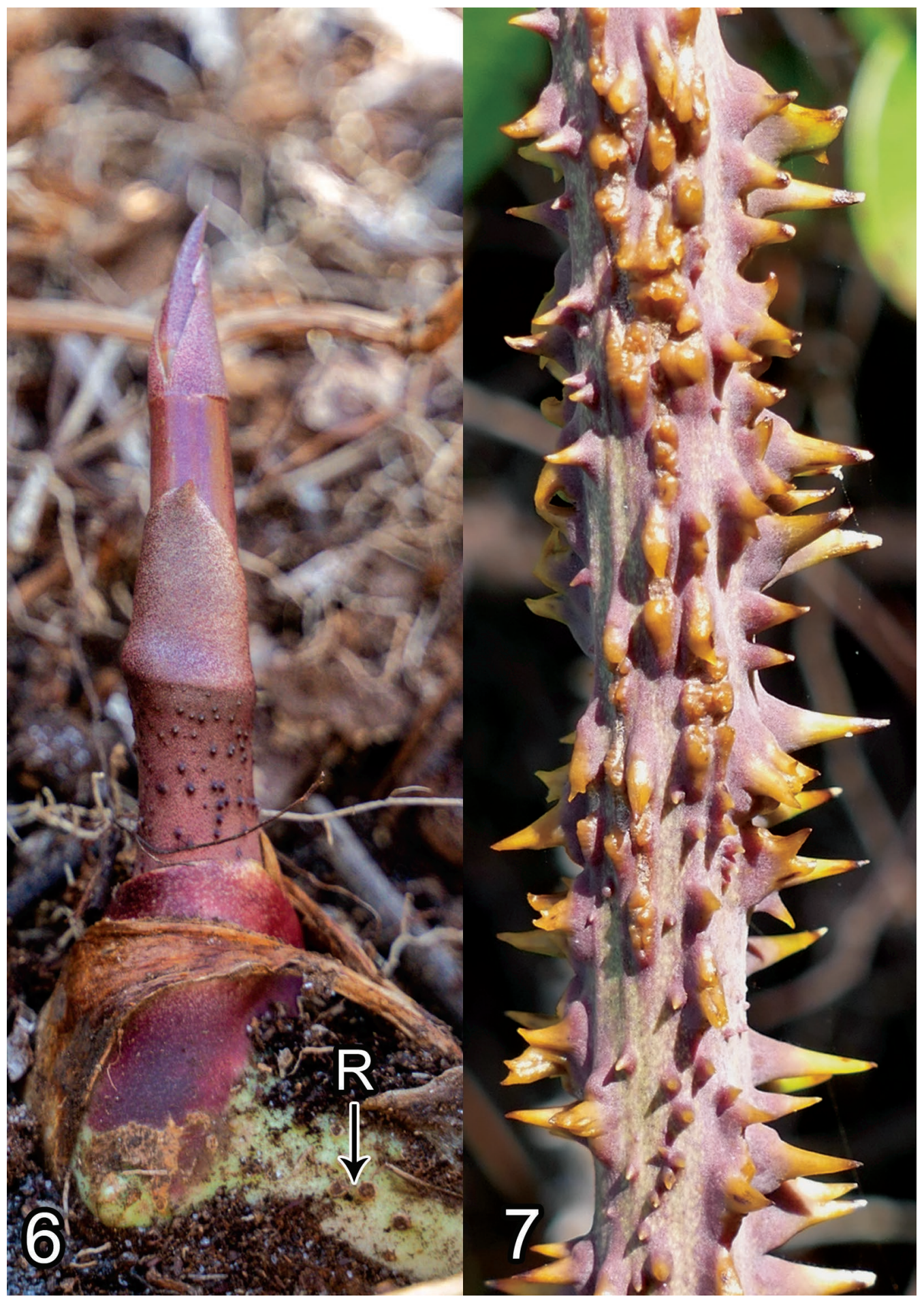

FIG. 6. Smilax auriculata. A portion of a rhizome (R) terminating in a short, vertical, recently initiated, type-1 stem. Photographic image by Mary Dominguez. FIG. 7. Smilax auriculata. A portion of a type-1 stem exhibiting numerous prickles. Photographic image by Jean McCollom. 


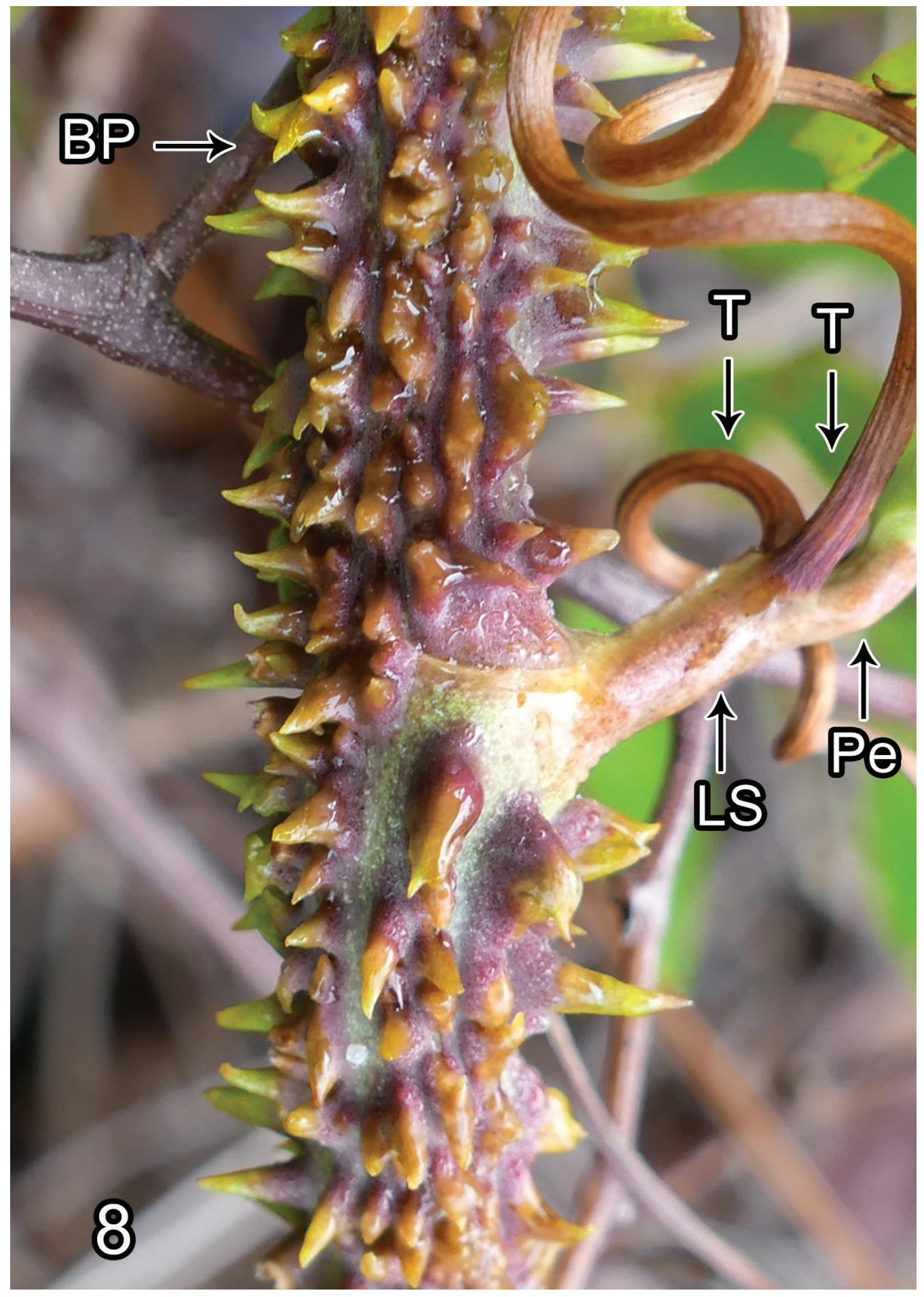

FIG. 8. Smilax auriculata. A portion of a type-1 stem exhibiting numerous prickles and the basal portion of a foliage leaf. BP, branched prickle; LS, leaf sheath; Pe, petiole; T, tendril. Photographic image by Jean McCollom. 


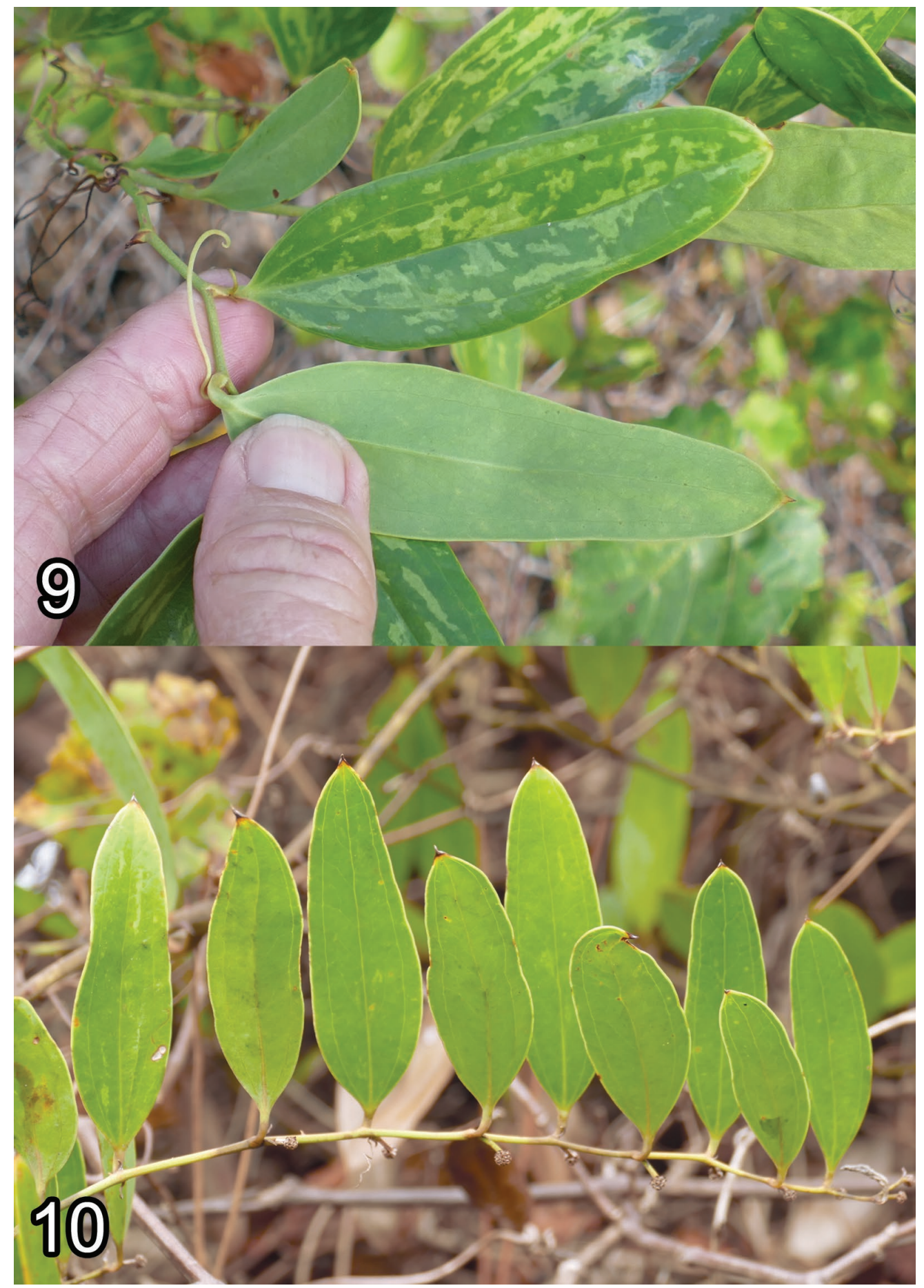

FIG. 9. Smilax auriculata. A portion of a type- $\underline{3}$ stem (at left) bearing two large foliage leaves (at center), these leaves appearing in adaxial view (upper leaf) and abaxial view (lower leaf). Photographic image by Jean McCollom.

FIG.10. Smilax auriculata. A portion of a type-3 stem having its foliage leaves directed skyward. Photographic image by Jean McCollom. 


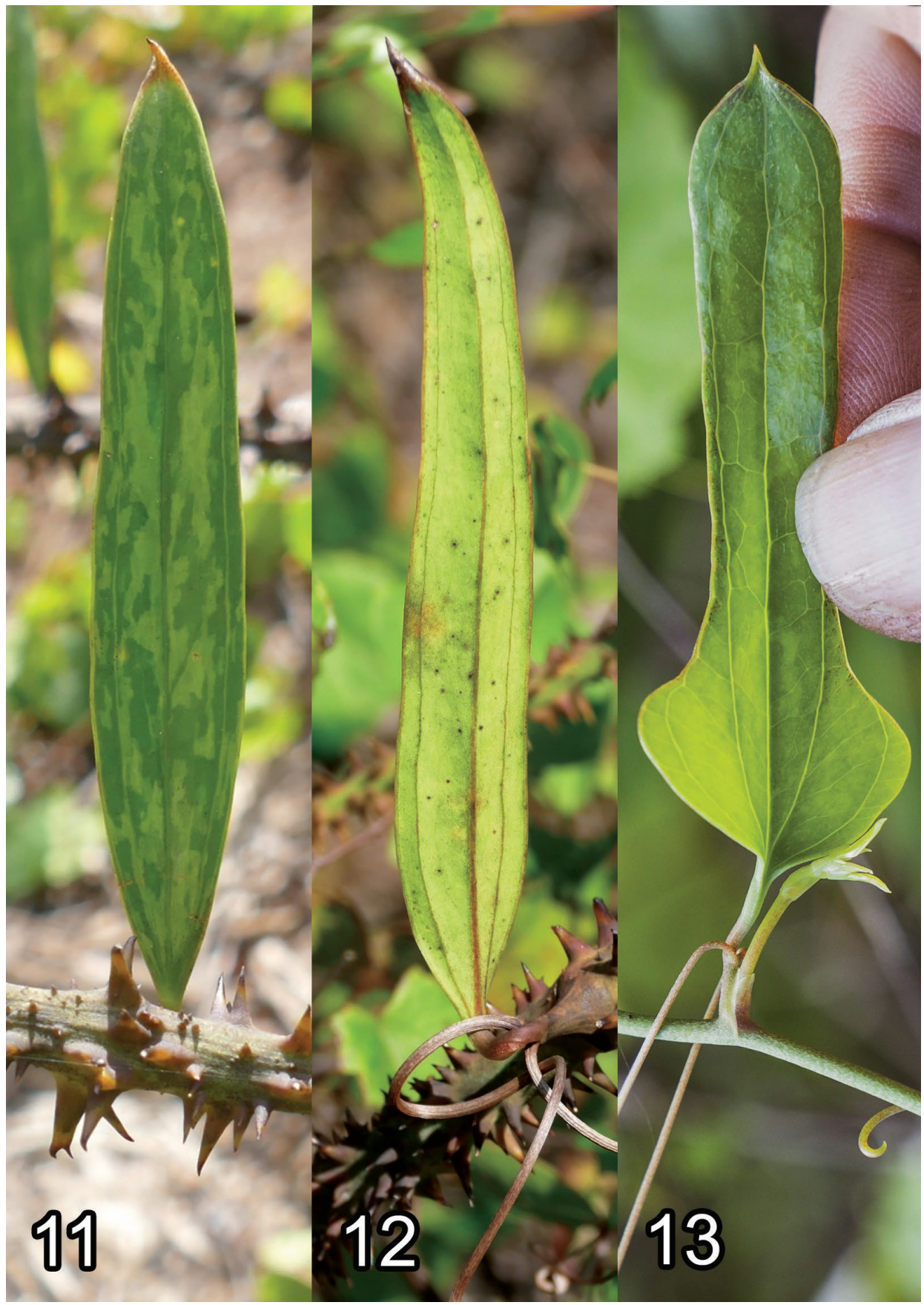

Fig. 11. Smilax auriculata. A narrow foliage leaf in adaxial view, attached to a portion of a type-1 stem. The lamina is straight, except for its apex which is bent leftward. Photographic image by Jean McCollom.

FiG. 12. Smilax auriculata. Another narrow foliage leaf, in abaxial view, attached to a portion of a type-1 stem. The lamina is conspicuously falcate. Photographic image by Jean McCollom.

FiG. 13. Smilax auriculata. A foliage leaf in adaxial view, attached to a type- $\underline{3}$ stem. The lamina is straight and lobed, basally. Photographic image by Mary Dominguez. 


\section{Types of aerial stems vs. orders of branching}

I observed five orders of branching within the above-ground branching system. A first-order stem is a type- $\underline{1}$ stem emergent from the ground. A second-order stem is formed from an axillary bud of a first-order stem; a third-order stem develops from an axillary bud of a second-order stem, and so forth.

A type- $\underline{1}$ stem is either a first-order- or a second-order stem. A type- $\underline{2}$ stem (except for one that intergrades with a type- $\underline{1}$ stem) is a second-order- or a third-order stem. Type- $\underline{\underline{3}}$ stems are normally stems of higher order and are, by far, the most abundant of vegetative axes of the above-ground branching system.

\section{Aspects of branching of type-3 stems}

On Dec. 11, 2018 (a date following the end of the growing season) I collected a number of type- $\underline{3}$ stems. Later, in the laboratory I examined the axils of 40 well-developed foliage leaves, thereof, which did not subtend expanded vegetative axes. Each foliage leaf subtended a dormant vegetative lateral bud, i.e., either a solitary bud ( $\mathrm{n}=20$ leaves; Fig. 1, DVLB) or a bud together with a dead, post-mature infructescence ( $\mathrm{n}=20$ leaves). In the latter case, within the leaf axil the infructescence was superposed over the vegetative bud.

Whether it is solitary in a leaf axil or paired with an infructescence, a dormant vegetative lateral bud may expand into a mature, higher-order type- $\underline{3}$ stem. Expansion is intravaginal (i.e., located between the parent stem and the subtending leaf sheath).

Consider a type- $\underline{3}$ stem (stem $\underline{A}$ ) which bears an expanded type $\underline{3}$ stem (stem $\underline{B}$ ) derived from a solitary vegetative lateral bud (Fig. 1, type- $\underline{3}$ stem $\underline{B}$ [right]). Stem $\underline{B}$ bears a prophyll ( $\underline{P}$ ) just above its base. Like the prophyll of a rhizome (as well as the prophyll of a type- 2 stem), the prophyll is a scale leaf situated in the typical prophyllar position for monocotyledons; it ranges from 3 to $3.5 \mathrm{~mm}$ long ( $\mathrm{n}=7 ; \tilde{x}=3 \mathrm{~mm}$ ).

Now consider the case where a foliage leaf of stem $\underline{A}$ subtends an infructescence (I) superposed over type-3 stem $\underline{B}$ (Fig. 1, Type- $\underline{3}$ stem $\underline{B}$ [left]). I interpret the infructescence as an axillary branch, rather than as terminal, based on: $\mathbf{a}$. its axillary position, and $\mathbf{b}$. the absence, on stem $\underline{\mathrm{A}}$, of a prophyll facing the infructescence. Surprisingly, the infructescence lacks a prophyll. On the other hand, stem $\underline{B}$ manifests a prophyll (P) morphologically like the prophyll described above, which has the median of its abaxial surface facing the inflorescence peduncle. Based on that prophyllar position I interpret stem $\underline{B}$ as a supernumerary branch of the inflorescence rather than as a branch derived directly from stem $\underline{A}$. Stem $\underline{B}$ in this case manifests, essentially, the same morphology as stem $\underline{B}$ derived from a solitary vegetative lateral bud.

Present findings conform with Troll's (1937) statement that Smilax and Dioscorea, by producing superposed buds, are the sole exceptions to the rule that collateral buds are the only kind of supernumerary buds present among monocotyledons.

\section{Precocious stems, prolepsis, and syllepsis}

Consider an immature, elongating type- $\underline{3}$ stem (stem $\underline{A}$ ) derived from a dormant vegetative lateral bud. As indicated, certain vegetative lateral buds of stem $\underline{A}$ may themselves become dormant until the following growing season. Commonly, though, other lateral bud(s) of stem $\underline{A}$ is/are non-dormant and begin to expand into new type- $\underline{3}$ stem(s) before stem $\underline{A}$ has itself ceased to elongate. I call those stems that arise from the non-dormant buds "precocious stems."

Fifteen type- $\underline{3}$ stems derived from dormant axillary buds were monitored during the same growing season in which they had expanded. Disregarding leaves and dormant buds, the individual stems gave rise either to precocious stems, to inflorescence(s), to precocious stems and inflorescences, or to neither precocious stems nor inflorescences. The number of precocious stems per type- $\underline{3}$ stem varied from 0 to $11(\tilde{x}=2)$. The single type- $\underline{3}$ stem that bore eleven precocious stems was unique, because some of its precocious stems themselves bore precocious stems of the next higher order (five higher-order stems in one case). Also, a precocious stem of another type- $\underline{3}$ stem was unique in bearing inflorescences.

Hallé et al. (1978) recognized "two generally contrasted types of lateral branching" in woody angiosperms: syllepsis (which yields sylleptic vegetative branches) and prolepsis (which yields proleptic vegetative branches). They distinguished between those types according to development and morphology. Development.-Syllepsis 
is the continuous development of a stem from a lateral meristem, i.e., the meristem manifests no evident intervening dormant period. By contrast, in prolepsis the lateral meristem undergoes a period of dormancy before elongating into a stem. Morphology.-Hallé et al. (1978) stated that the following distinctions apply in the "majority of examples." Sylleptic branches lack bud scales, and in size and shape the first leaf (or leaf pair) of a sylleptic branch more-or-less resemble(s) a normal foliage leaf. A sylleptic branch also exhibits an extended hypopodium (i.e., the stem sector situated subjacent to the prophyll[s]). By contrast, proleptic branches exhibit one or more basal bud scales and, usually, a series of transitional leaves inserted between the bud scales and ordinary foliage leaves. Also, proleptic branches manifest a short hypopodium.

In S. auriculata, a type- $\underline{3}$ stem derived from a dormant lateral bud is, by developmental definition, a proleptic branch. Too, the prophyll of the bud is interpretable as a bud scale, being a persistent scale leaf which encloses the remainder of the bud. And in keeping with prolepsis, the hypopodium is relatively short, both before and after the type- $\underline{3}$ stem has elongated.

In contrast, the precocious stems of S. auriculata match the developmental definition of sylleptic branches, because they expand without an intervening dormant period; however, they differ morphologically from sylleptic branches, at least from stereotypical ones, because their prophylls are scale leaves and because the precocious stems manifest short hypopodia. Thus, those stems are called precocious, rather than sylleptic, branches, herein.

\section{Phyllotaxy and zig-zag growth}

Phyllotaxy of the foliage leaves is always alternate but varies in detail. It is commonly orthodistichous on type- $\underline{3}$ stems (i.e., the foliage leaves compose two orthostiches).

Type- $\underline{3}$ stems normally exhibit zig-zag growth, whereas, on type- $\underline{2}$ and type- $\underline{1}$ stems such growth is either less pronounced (on some type- $\underline{2}$ stems) or absent (on other type- $\underline{2}$ stems and on type- $\underline{1}$ stems). In zig-zag growth the stem long axis shifts direction at each node, rather than remaining straight. Consider a type- $\underline{3}$ stem with zig-zag growth, viewed in the standard orientation. Progressing acropetally on that stem, at each node of the left orthostiche the stem is bent rightward; at each node of the right orthostiche the stem is bent leftward.

\section{Determinate growth}

Although, type- $\underline{3}$ stems bear evergreen foliage leaves, those stems have determinate growth - a conclusion based on observations of Dec. 11, 2018 (a date which, as indicated above, transpired after the growing season). On that date most of those stems manifested abortive/dead tips, and the remaining type- $\underline{3}$ stems each appeared to terminate in a post-fruiting, dead infructescence.

Subsequent preliminary observations of May 15, 2019 revealed dead tips on some type- $\underline{3}$ stems that had expanded from dormant vegetative lateral buds earlier in the same growing season. Thus, at least some type- $\underline{3}$ stems permanently cease growing during the same growing season in which they began to elongate.

The origin of higher-order stems from determinate lower-order stems is a kind of sympodial growth. It recalls the death of twig tips and the subsequent expansion of pseudoterminal buds in various dicotyledonous species.

I observed two additional, relevant features on that date. a. On some type- $\underline{3}$ stems the distal-most leaves and infructescences were highly reduced, compared to their counterparts borne more proximally on the stems. b. The distal internodes of the stems were shorter than the more proximally situated ones.

Most of the clump of S. auriculata presently studied was stratified, exhibiting an upper layer of living, higher-order stems, and a subjacent, much thicker layer of predominantly dead stems that were also mainly of higher-order. The existence of the dead stems suggests two additional conclusions. a. Because stems die, there is likely an upper limit to the number of orders of living branches present. Indeed, as stated above, fifth-order stems were the highest branching-order presently recognized. b. For clumps of S. auriculata growing in the open, i.e., away from trees (like most of the clump described here), as new stems develop, older stems apparently die and become part of the lower, predominantly dead layer. Those events would yield an apparent, gradual shift upward of the upper layer of living stems. 
It was difficult to locate the distal ends of some type- $\underline{1}$ and type- 2 stems, but on Dec. 16, 2018, the tips of four type- $\underline{2}$ stems were found which bore expanding foliage leaves. By manifesting living tips at that time of year, those stems differed from the determinate type- $\underline{3}$ stems, aforementioned, and evidently served as overwintering structures.

Additional comment and comparison with previous findings.-One might speculate that the death/ abortion of type- $\underline{3}$ stem tips simply result from winter-cold, rather than being inherent features of S. auriculata. Two circumstances, aforementioned, contradict that conclusion: a. unlike the stem tips, the axillary vegetative buds become dormant and remain alive during the winter, and $\mathbf{b}$. at least some of the stem tips die before winter, i.e., during the same growing season in which the stems become expanded.

Martin (1975) and Martin and Tucker (1985) undertook developmental studies, collectively, of Smilax bona-nox, Smilax laurifolia, Smilax pumila, Smilax rotundifolia, and Smilax smallii. Of those five species, both workers reported determinate growth solely in S. pumila. Martin and Tucker (1985) characterized it as "... shoot-tip abortion involving a cessation of vegetative growth ..." They deemed their finding as "... the first report of shoot tip abortion in a monocotyledon."

Thus, Smilax auriculata is the second Smilax species known to have determinate growth. Therefore, present findings update Judd's (1998) statement that-of the species of sect. China of the genus Smilax within the southeastern United States-Smilax pumila is the sole species with determinate growth. In fact, S. auriculata belongs to sect. China. In the southeastern United States, sect. China also includes S. bona-nox, S. glauca, S. laurifolia, S. pumila, S. rotundifolia, S. smallii, S. tamnoides, and S. walteri (Judd 1998).

\section{Foliage leaf}

The foliage leaf consists of a leaf sheath, two tendrils, a petiole, and a lamina. Herein I call the petiole and leaf sheath, collectively, the petiole-sheath axis. That axis varies in color; it may be pink or green distally and either dark gray, reddish, or gray and reddish-gray, basally.

In cross section, the basal portion of the leaf sheath is crescent-shaped, whereas, the distal part is ca. terete and much like the petiole in size and shape. The sheath is thickest medially, where it manifests living tissue. By contrast, its marginal and submarginal parts are membranous, brown, and apparently dead. The sheath margins are sometimes very short-fimbriate or inconspicuously lacerate. Basally, each side of the sheath is attached to the associated stem, along a separate line that extends part-way around the stem (Fig. 8, LS); however, the two lines of sheath-attachment are too short to unite or overlap on the leaf-opposed surface of the stem. Distally, the sheath margins converge to a point on the adaxial leaf surface, situated midway between the loci of insertion of the tendrils.

The leaf sheath encloses, or partially encloses, axillary bud(s). Its tough consistency and its tight appression to the bud(s) suggest that it gives it/them mechanical protection.

The tendrils are inserted side-by-side on the adaxial leaf surface at the junction of the sheath and petiole (Fig. 8). Tendrils are generally well-developed on leaves from type- $\underline{1}$ and type- $\underline{2}$ stems, but on leaves from type-3 stems many (but not all) of the tendrils are short or rudimentary. Some tendrils become coiled around objects; others situated away from objects may also become considerably, albeit irregularly, coiled. The longest tendrils measured (from the foliage leaves of type- $\underline{1}$ stems) were $25 \mathrm{~cm}$ long. Individual tendrils are green, yellow, purple, or a mixture of green and purple.

The petiole is essentially terete, but manifests two low ridges—one to each side—along its entire length. Each ridge is confluent with a separate margin of the lamina; however, the ridges are not continuous with the margins of the leaf sheath.

The lamina is coriaceous. Also, in adaxial view the living lamina varies from conspicuously to inconspicuously mottled; the mottling is light green against a dark green background (Figs. 9, 11). By contrast, the living lamina in abaxial view is either light green and non-mottled (Figs. 9, 12), or it exhibits inconspicuous mottling which is configured differently from that observed in adaxial view. Also, mottling is less apparent in dried specimens. 
Certain taxonomists have utilized differences in the venation of foliage leaves to distinguish between Smilax species (e.g., Clewell 1985; Godfrey \& Wooten 1979; Wunderlin \& Hansen 2011). During the present study, venation was best observed in dried, rather than in living laminae. Described, below are 15 dried foliage leaves from types $\underline{1}$ to $\underline{3}$ aerial stems derived from four collections (Wilder $\&$ McCombs 41594, 41596, 41597, 41739).

The lamina contains five longitudinal veins (a midvein, two lateral veins, and two submarginal veins) plus a reticulum of higher-order veins. The midvein is the thickest vein, at least partway along its length. Each lateral vein intervenes between the midvein and the associated submarginal vein. Each submarginal vein extends along a separate lamina margin. It often extends submarginally for its entire length, but sometimes assumes its submarginal position distal to the base of the lamiina (Fig. 13). Sometimes, also, the lamina margins are thickened. Then, characteristically, a narrow groove demarcates a submarginal vein from the associated lamina margin.

In living foliage leaves in nature the longitudinal veins are most evident when observed with transmitted sunlight (Fig. 10) rather than with reflected light. In the living lamina viewed with reflected light, a prominent midvein and sometimes, also, two less prominent lateral veins is/are outwardly evident (Figs. 9, 11, 12). Some broad, living laminae manifest both submarginal veins, as well (Fig. 13).

Many laminae which arise from type- $\underline{3}$ stems are lanceolate (Figs. 9, 10); however, the laminae as a whole range from lanceolate, to elliptic, to oblong and from narrow to broad in all three configurations. Rarely, the lamina is lobed, basally (Fig.13). Subsequent discussion is solely of the unlobed laminae.

The lamina varies from straight to conspicuously falcate (Fig. 12), and the lamina apex may extend forward or sideways (Fig. 11). The apex is subulate, ranges from narrowly to broadly acuminate, and culminates in a dead mucro (precursor tip) which is often broken away. Also, within the acuminate zone there exists additional dead tissue which is continuous with the dead mucro. Basally, the lamina ranges from narrowly to broadly cuneate. The lamina margins are entire, may be developed as thick bands (on large laminae), are pale, and are neither involute nor revolute.

Thirty living foliage leaves were selected for measurement because of their considerable variation in size and shape, rather than at random. For each parameter listed, the range and median value of measurements are indicated between parentheses: sheath length $(1.5-19 \mathrm{~mm} ; \tilde{\mathrm{x}}=7.5 \mathrm{~mm})$, petiole length $(2-10.5 \mathrm{~mm} ; \tilde{\mathrm{x}}=5.0$ $\mathrm{mm})$, lamina length $(51-152 \mathrm{~mm} ; \tilde{x}=99 \mathrm{~mm})$, and lamina width $(10-56 \mathrm{~mm} ; \tilde{\mathrm{x}}=27)$. The ratio of sheath length to petiole length varied from 0.43 to $3.0(\tilde{x}=1.5)$. The ratio of lamina length to lamina width ranged from 1.9 to $9.4(\tilde{x}=3.6)$. Also, type- $\underline{1}$ stems frequently bore foliage leaves with especially high ratios of lamina length to lamina width (Figs. 11, 12).

On living type- $\underline{1}$ and type- $\underline{2}$ stems the lamina of a foliage leaf may break away, leaving behind a persistent petiole-sheath axis and the attached tendrils.

Comparison with previous findings.-Mottled foliage leaves are, apparently, atypical of S. auriculata. Of the authors referenced herein, solely Bullard and Allen (2013) reported mottled ("varigated" [sic]) leaves in this species, and they characterized them as rare. I have also observed mottled foliage leaves on some plants of S. auriculata growing on Sanibel Island (Lee Co., Florida). Unlike S. auriculata, Smilax bona-nox, Smilax glauca, and Smilax smallii often produce mottled foliage leaves (Bullard \& Allen 2013).

Virtually all laminae presently observed were unlobed and none was hastate. Yet, for S. auriculata: a. Godfrey (1979) reported the laminae as being "... without lobes at the base, or with varying degrees of basal lobing to definitely hastate ...", b. Correll and Correll (1982) described the laminae as "... often somewhat dilated to auricled below the middle or slightly pandurate," and c. Clewell (1985), Duncan (1975), and Radford et al. (1968) characterized the laminae as being often hastate. Coker (1944) indicated two formas of S. auriculata with laminae comparable to those reported presently. In one forma, "all the rather large leaves [were] entirely without any expansion at the base." In the other forma "... very few [of the leaves manifested] any tendency to lobing at the base."

Whereas, I observed solely five longitundinal veins per lamina, Morong (1894) reported from three to five in S. auriculata. 
The uniqueness and nature of tendrils of Smilax.-Smilax and the previously recognized genera Heterosmilax and Pseudosmilax are the sole monocotyledons to produce tendrils (Troll 1937). Earlier workers variously interpreted the tendrils of Smilax: $\mathbf{a}$. as stipules; $\mathbf{b}$. as the lateral leaflets of a ternate leaf (in that interpretation the lamina would be the terminal leaflet); c. as emergences or even modified prickles ("Emergenzdornen," "Stacheln"), or; d. as organs derived sui generis (Troll 1937). Also, Arber (1920, 1925), consistent with her phyllode theory (see below), attributed the tendrils to "chorosis [or] dedoublement," i.e., to division of a petiole. Those alternatives are not explored, herein.

\section{Tendencies for the bending and orientations of foliage leaves}

Foliage leaves bend during growth, but the manner and extent of bending and their resulting orientations are variable. Never-the less, certain tendencies are frequent. I discuss the frequent tendencies, below.

The tips of foliage leaves are typically directed skyward or approximately so (Fig. 10). The skyward orientations might benefit the leaves by increasing their likelihood of, and/or their degrees of, exposure to direct sunlight.

Consider a type- $\underline{3}$ stem which grows more-or-less horizontally and is positioned in the standard orientation. Consider, too, a young foliage leaf from that stem. Three kinds of bending account for the skyward orientation of that leaf. a. The leaf sheath bends laterally, away from the parent stem, to an angle of up to $90^{\circ}$. $\mathbf{b}$. The petiole bends in the adaxial direction, i.e., toward the parent stem. c. The petiole may also bend backward relative to the apex of the parent stem. The petiole bends either at its basal end and/or more distal, thereto.

Because the petiole bends away from the plane of the leaf sheath, the mature foliage leaf appears geniculate.

Also, because the foliage leaves of the type- $\underline{3}$ stem are bent as described above, and because the stem exhibits orthodistichous phyllotaxy, the leaf-laminae within both orthostiches become oriented along, and parallel to, a vertical/near-vertical plain situated between the orthostiches.

Consider the stem in side view (Fig. 10). The laminae of the foliage leaves from one orthostiche may appear to interdigitate with, or partially overlap with, the laminae of the leaves of the other orthostiche. In each orthostiche the adaxial surfaces of the laminae face the other orthostiche of foliage leaves. Thus, within each orthostiche the abaxial lamina surfaces are directed outward, away from the vertical/near-vertical plane, aforementioned. By being directed away from the mass of leaves on the parent stem, the abaxial lamina surfaces might encounter greater air flow than do the adaxial surfaces. I briefly investigated the relative concentrations of stomata within epidermal peels from the laminae of foliage leaves from type- $\underline{3}$ stems. I observed abundant stomata in the abaxial epidermis, but saw none within the adaxial epidermis. Thus, for the foliage leaves of type-3 stems the outward-orientations of the abaxial lamina surfaces might faciliate gas exchange between the leaves and the atmosphere.

Comparison with previous findings. - Bullard and Allen (2013) tabulated the orientations of mature foliage leaves within woody species of Smilax. Similar to present findings, they characterized the leaves as "often ascending" in S. auriculata. They also indicated foliage leaves as ascending (S. smallii), as "often erect" (S. laurifolia), and as not ascending (S. bona-nox, S. pumila, S. rotundifolia, S. tamnoides, and S. walteri).

\section{Prophyll of type- $\underline{3}$ stems}

Morphological aspects of the prophyll of an expanded type- $\underline{3}$ stem are listed. a. It is segmented into a thin, brown distal sector and a thicker, fleshy, light-green basal part. b. Its apex is gently rounded or slightly retuse, and is apiculate. c. The distal sector of the prophyll is often inconspicuously bicarinate, and both carinae converge at the apiculus. d. The prophyll margins likewise meet at the apiculus and, also, are fused together basally on the opposite side of the prophyll. e. Outwardly, the prophyll appears continuous with, rather than being articulate with, the hypopodium (Fig. 1, H). f. Collectively, the hypopodium, which is light-green, and the light-green sector of the prophyll appear swollen and pulvinus-like. g. The prophyll is persistent and, aside from its apiculus, it tightly clasps its parent stem. Likewise, the sheath of the foliage leaf which subtends its parent stem tightly clasps both the prophyll and the base of its parent stem. 


\section{Heterophylly}

Discussed below are variations of leaf form not considered above.

Type-1 stems.-Heterophylly is conspicuous. In acropetal sequence, a type- $\underline{1}$ stem produces scale leaves (comparable morphologically to the non-prophyllar scale leaves of the rhizome), transitional leaves, and foliage leaves.

Consider part of the leaf sequence observed on a representative type- $\underline{1}$ stem. The leaves are numbered and described in acropetal order, beginning with the basal-most leaf visible aboveground (Fig. 14). Leaf nos. $\underline{1}$ to $\underline{4}$ are scale leaves $1.8,2.4,2.5$, and $2.5 \mathrm{~cm}$ long, respectively. Leaf nos. $\underline{5}$ and $\underline{6}$ are transitional leaves 2 and $5.3 \mathrm{~cm}$ long, respectively. Leaf nos. 7 to 10 are foliage leaves $8.4,6.0,9.0$, and $8.5 \mathrm{~cm}$ long, respectively.

Scale leaf no. 1 manifests a sheath damaged at its tip (Fig. 14A). Scale leaf nos. $\underline{2}$ to $\underline{4}$ each consist of a relatively long sheath and an ensiform tip that measures 0.5, 2, and $3 \mathrm{~mm}$ long, respectively (Figs. 14B-14D).

The first-formed transitional leaf (leaf no. $\underline{5}$ ) manifests a sheath $2 \mathrm{~cm}$ long and a stout tendril $12 \mathrm{~cm}$ long inserted upon the sheath, just beneath the tip of the sheath (Figs. 14E, 14F). The central axis of the secondformed transitional leaf (leaf no. 6) exhibits, in acropetal sequence, a sheath $2 \mathrm{~cm}$ long, an ensiform sector 0.3 $\mathrm{cm}$ long, and a narrow, terete (unifacial) lamina $3 \mathrm{~cm}$ long. As well, at the base of the lamina, leaf no. $\underline{6}$ bears a solitary, stout tendril ca. $24 \mathrm{~cm}$ long (Fig. 14G).

Leaf no. $\underline{I}$ is a depauperate foliage leaf. Its central axis consists of a sheath, petiole, and lamina which measure 2, 0.4 , and $6 \mathrm{~cm}$ long, respectively. The lamina manifests a basal, bifacial portion $4.3 \mathrm{~cm}$ long and a distal, ensiform part (precursor tip) $1.7 \mathrm{~cm}$ long. The bifacial portion is narrow $(0.35 \mathrm{~cm}$ wide) compared to that of typical foliage leaves. At the junction of its sheath and petiole, leaf no. $\underline{I}$ also bears two stout tendrils ca. 24.5 and $25 \mathrm{~cm}$ long, respectively (Fig. 14H). Leaf nos. $\underline{8}$ to $\underline{10}$ (not illustrated) are foliage leaves morphologically comparable to leaf no. $\underline{7}$, but with broader laminae.

Type-2 stems.-Heterophylly is less pronounced. The leaf formed immediately after the prophyll (leaf no. 2) manifests a sheath, sometimes a petiole, two tendrils, and a unifacial or bifacial lamina. Leaf no. $\underline{3}$ is generally a foliage leaf, i.e., it bears the four main parts of a foliage leaf (including a pair of tendrils) and has a bifacial lamina. The subsequently formed leaves are typical foliage leaves.

On leaf nos. $\underline{2}$ and $\underline{3}$, various structures—particularly the tendrils—may appear reduced.

Type- $\underline{3}$ stems. - As a rule they produce typical foliage leaves immediately after the prophyll, but they sometimes bear scale leaves, distally.

Heterophylly and the phyllode theory.-Agnes Arber (1925), building on the ideas of previous workers, advanced her phyllode theory. She maintained that the foliage leaves of monocotyledons are phyllodes (leaves lacking a true lamina), unlike the foliage leaves of typical dicotyledons. She interpreted the monocotyledonous lamina as a modified/elaborated petiole (i.e., as a so-called "pseudolamina"), stating that "we ... take a leaf-base [leaf sheath] terminating in a simple petiole as the fundamental Monocotyledonous type ..." (language in brackets mine). Arber (1925) could have bolstered her theory by referencing the transitional leaves of S. auriculata (e.g., leaf no. $\underline{6}$ in the representative series described above). Their laminae: a. are petiole-like (by being unifacial or intermediate between unifacial and bifacial), and $\mathbf{b}$. are serially homologous to the primarily bifacial laminae of the foliage leaves. Later, Arber $(1950: 85,108)$ renounced her theory, and it is not defended here despite the supporting evidence, aforementioned.

\section{Bilateral and mirror-image symmetry within the above-ground branching system}

Consider again a type- $\underline{3}$ stem in the standard orientation. Two manifestations of bilateral symmetry occur. a. Away from the distal sector of the stem those axillary inflorescences associated with the left orthostiche extend leftward ( $n=21)$, whereas those axillary inflorescences associated with the right orthostiche extend rightward $(n=20)$. b. Similarly, axillary type- $\underline{3}$ branches associated with the left- and right orthostiches extend leftward and rightward, respectively ( $\mathrm{n}=13$ in each case).

Consider, too, a type $\underline{3}$ stem (stem $\underline{\mathrm{A}}$ ) positioned in the standard orientation, that bears an additional type- $\underline{-}$ stem (stem $\underline{B}$ ). If stem $\underline{B}$ originates axillary to a foliage leaf from the left orthostiche of stem $\underline{A}$, and if stem 


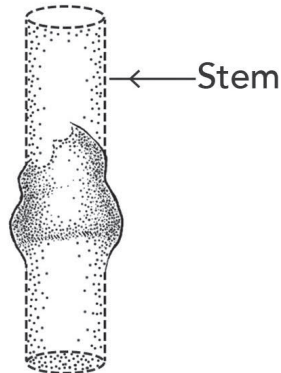

A

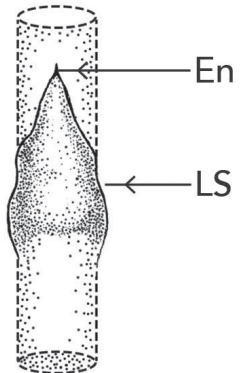

B

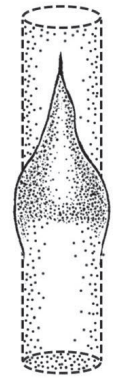

C
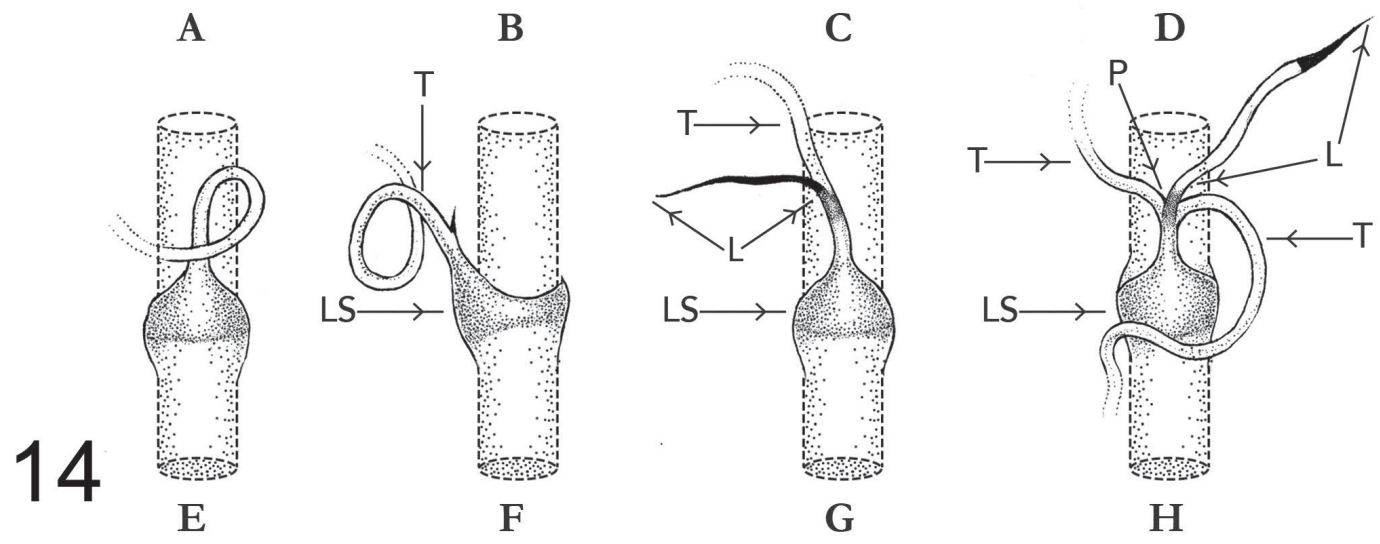

FIG. 14. Smilax auriculata. The basal-most seven leaves of a representative type-1 stem. Drawings $A$ to $H$ represent the leaves in acropetal order on the stem, and each leaf is illustrated together with its associated stem portion. Drawings $A-D, G-H$ depict separate leaves in abaxial view, whereas, drawings $E-F$ depict another leaf in abaxial view and in side view, respectively. The leaf in drawing $A$ is damaged and lacks its distal end, whereas, each remaining leaf manifests a unifacial (ensiform or terete) distal portion which is drawn in solid black. Only the basal portions of tendrils are illustrated. The leaves are not drawn to scale. A-D. Leaf nos. 1 to $\underline{4}$, respectively. Each leaf is a scale leaf. E-F. Leaf no. $\underline{5}$. A transitional leaf consisting of a leaf sheath and a single tendril inserted just below the tip of the sheath. The tip of the sheath is hidden in drawing $E$ but visible in drawing $F$. G. Leaf no. 6. A transitional leaf manifesting a leaf sheath, a single tendril, and a unifacial lamina. H. A depauperate foliage leaf consisting of a leaf sheath, two tendrils, a petiole, and a lamina. The lamina is mostly bifacial but manifests a unifacial distal portion. En. Ensiform tip of scale leaf. L. lamina. LS. Leaf sheath. P. Petiole. T. Tendril. Drawings by Kristen Camisa.

$\underline{B}$ is then positioned in the standard orientation, then the first foliage leaf of stem $\underline{B}$ will be in the right orthostiche of stem $\underline{B}(\mathrm{n}=24$ out of 27 cases; Fig. 1, Type- $\underline{3}$ Stem $\underline{B}$ [left]). If stem $\underline{B}$ originates axillary to a foliage leaf from the right orthostiche of stem $\underline{A}$, and if stem $\underline{B}$ is positioned in the standard orientation, then the first foliage leaf of stem $\underline{B}$ will appear in the left orthostiche of stem $\underline{B}$ ( $n=20$ out of 23 cases; Fig. 1, Type- $\underline{3}$ Stem $\underline{B}$ [right]). Those correlations are not absolute, apparently, because of shifts in the directions of growth of type- $\underline{3}$ stems.

The prophyll and the first-formed foliage leaf of stem $\underline{B}$ represent the beginning of, and define the direction of, a helix (genetic spiral) of the leaves on stem $\underline{B}$. If stem $\underline{B}$ is viewed in the standard orientation, and if the firstformed foliage leaf appears in the left orthostiche of stem $\underline{B}$, then-proceeding from the prophyll to that foliage leaf - the phyllotactic helix is established as clockwise (Fig. 1, Type- $\underline{3}$ Stem $\underline{B}$ [right]). If the foliage leaf appears in the right orthostiche on stem $\underline{B}$, then the helix is established as counterclockwise (Fig. 1, Type- $\underline{3}$ Stem $\underline{B}$ [left]). Thus, based on phyllotaxy, vegetative axis(es) subtended by foliage leaves of the left orthostiche of stem $\underline{A}$ are mirror images of those subtended by foliage leaves of the right orthostiche of stem $\underline{A}$.

By comparison, Wilder (1976, 1977a, 1977b, 1981a, 1981b) observed a different manifestation of mirrorimage symmetry in certain species of Cyclanthaceae (Monocotyledoneae). In those cases, on a shoot or a portion of shoot with clockwise phyllotaxy, all first-order vegetative lateral buds exhibited counterclockwise phyllotaxy, 
and vice versa. By contrast, and as indicated, in S. auriculata, on a vegetative branch of a type- $\underline{3}$ stem the direction of phyllotaxy depends on whether the branch develops from an axillary bud aligned with either the left or the right orthostiche of foliage leaves of the type- $\underline{3}$ stem.

\section{Inflorescence}

The inflorescence is a pedunculate umbel. The peduncle culminates in a torus which is broader than the peduncle and which appears globose at post-fruiting stage. A whorl of 5 to 7 fleshy bracts arises from the periphery of the torus $(\tilde{x}=6 ; n=10)$, and additional, centripetally situated, minute, ciliolate bracteoles encircle the base of each pedicel. The bracts and bracteoles are the positional equivalents of the phyllaries and chaff, respectively, of the heads of various Asteraceae (albeit, no phylogenetic relationship is implied herein).

The bracteoles subtending each pedicel delimit a cavity which contains the pedicel-base and which might be misinterpreted as a pit within the torus. Perhaps, that circumstance accounts for Morong's (1894) report of "pits or foveolae" within the torus of Smilax species.

The number of well-developed flower buds per umbel (excluding abortive flower buds) ranges up to 21 .

Inflorescences develop, apparently, solely on type- $\underline{3}$ stems. On expanding, proleptic type- $\underline{3}$ stems they expand concurrently with any precocious vegetative branches, thereof. Most inflorescences are borne axillary to foliage leaves, but some are subtended by scale leaves situated at the distal end of the type- $\underline{3}$ stem. Occasionally, an inflorescence terminates a type- $\underline{3}$ stem.

On a stem the axillary inflorescences are often subtended by successively formed foliage leaves. For example, one stem exhibited a terminal inflorescence and, immediately proximal thereto, 11 successively formed foliage leaves which each subtended an inflorescence.

The following measurements are of aged axillary peduncles which manifested pedicel abscission scars on their tori: torus diameter $(2.5-3 \mathrm{~mm} ; \mathrm{n}=8)$ and peduncle length (including the torus; $6-16.5 \mathrm{~mm} ; \tilde{\mathrm{x}}=11 \mathrm{~mm}$; $\mathrm{n}=15$ ). The lengths of the petiole-sheath axes of the foliage leaves that subtended the peduncles ranged from 4 $\mathrm{mm}$ to $10.5 \mathrm{~mm}(\tilde{\mathrm{x}}=8 \mathrm{~mm} ; \mathrm{n}=15)$. The peduncles and petiole-sheath axes were, essentially, sub-equal, albeit, each peduncle was longer than its subtending petiole-sheath axis, by 0.5 to $6 \mathrm{~mm}(\tilde{\mathrm{x}}=2.75 \mathrm{~mm} ; \mathrm{n}=15)$.

The pedicels of preserved pistillate flowers at anthesis ranged from 3.5 to $6 \mathrm{~mm}$ long $(\tilde{x}=4.75 \mathrm{~mm} ; n=20$ pedicels from seven umbels).

Comparison with previous findings.-Coordinate with present observations, Bullard and Allen (2013) characterized the inflorescences of S. auriculata as both "terminal" and "axillary to the leaves," but they reported solely axillary inflorescences in eight additional woody Smilax species.

\section{Root system}

The root system is entirely underground, consisting of rhizome-borne adventitious roots and the lateral roots, thereof. Adventitious roots are infrequent, being inserted often singly, but in groups of up to four, at branching points within the rhizome system. They arise either from the base of a daughter rhizome $(n=10)$ or from that side of the parent rhizome located opposite the insertion point of the daughter rhizome $(n=3)$.

The adventitious roots are yellowish and lack prickles. As do rhizomes, they extend parallel to, and close beneath, the surface of the ground. One adventitious root (which was severed an unknown distance below its distal end) measured $141 \mathrm{~cm}$ long. The adventitious roots vary from 3.5 to $6 \mathrm{~mm}$ thick (as measured $1 \mathrm{~cm}$ distal to their basal ends; $\tilde{\mathrm{x}}=5.0 ; \mathrm{n}=10$ ) and do not change appreciably in thickness along their length. Their lateral roots are comparatively narrow.

\section{Prickles}

As indicated, prickles develop on subterranean rhizomes and on all three types of the aboveground stems. They are rigid, thick, and broadest basally (Figs. 7, 8). Where abundant, they are inserted around the entire stem circumference. Also, the prickles on type- $\underline{3}$ stems are shorter than, and are less stout than, the largest ones on type- $\underline{1}$ and type- $\underline{2}$ stems. Except where indicated, the following description is limited to the prickles of type-1 stems. 
Some prickles are straight and extend outward perpendicular to the nearest stem surface; other prickles intermixed with them are curved either toward or away from the stem apex, or are curved in intermediate directions. All prickles are laterally compressed relative to the stem long axis.

Prickles are unbranched or branched, and the prickles of both kinds are numerous. The branched prickles are commonly two-to-four tipped (Fig. 8, BP). Both the unbranched- and branched prickles vary greatly in length and girth; the longest (branched) prickle measured was $12 \mathrm{~mm}$ long. Although, many unbranched prickles are distinct, other unbranched and branched prickles are connate basally, composing discrete, short, low ridges of varying lengths. Those ridges parallel the long axis of the stem, and in one case six longitudinal ridges occupied the same transverse level of a stem.

On type- $\underline{3}$ stems, where prickles are sparse or absent, the observed prickles were solely unbranched and non-connate. Type- $\underline{2}$ stems, having intermediate concentrations of prickles, manifested both unbranched and branched prickles, but only a modicum of the prickles were branched and were connate, basally.

Possibly, what I interpret as a branched prickle is actually an assemblage of partially connate prickles-an interpretation supported by the obvious prickle-connation within the ridges.

I am unaware of how many plant species produce branched prickles and prickles which are connate basally into ridges; however, Ceiba speciosa (Bombacaceae), an arborescent, dicotyledonous species with secondary growth, bears on its trunk robust, hardened prickles that may manifest one or both condition(s). In that species the ridges may parallel, or be oriented obliquely to, the trunk long axis (George Wilder, personal observations of cultivated material at the Naples Botanical Garden).

In S. auriculata, on young, living, type- $\underline{1}$ and type- $\underline{2}$ stems (and on some dried specimens of such stems) the distal portions of the unbranched- and branched prickles are generally shiny and are either green, yellow, or yellow plus brown (Figs. 7, 8). In transversely sectioned prickles the yellow coloration is peripheral. By contrast, the basal portions of those prickles (including the ridges derived from prickle-connation), as well as the remaining stem surfaces, are duller and are either purplish or gray (Figs. 7, 8).

On type- 1 stems the dense concentration of the prickles, together with the large sizes of many of the prickles, indicate that the prickles, collectively, manifest ample surface area. That conclusion, coupled with the propensity of prickles to be green distally when young, suggests that they might play a considerable, if transient, role in photosynthesis. That role might compensate for the sparse distribution of foliage leaves on, and the tendency for the foliage leaves to be narrow on, the type-1 stems.

The basal sectors of living type- $\underline{1}$ and type- $\underline{2}$ stems, including their prickles, may blacken with age (Fig. 12).

Prickles undoubtedly provide protection from animals, especially herbivores. It appears advantageous that the lowest-order (types $\underline{1}$ - and $\underline{2}$ ) stems exhibit more prickles than do the higher-order (type- $\underline{3}$ ) stems. a. By repeated branching, a typical low-order stem and all stems derived directly and indirectly from it would, collectively, yield more biomass than would a higher-order stem and its own, lesser progeny of stems. Thus, an animal that would destroy a low-order stem would inflict more damage than one that would destroy a higherorder stem. b. As was indicated, many living, prickle-poor, type- $\underline{3}$ stems are confined within a stem-layer situated high above-ground. In that position they would be less vulnerable and would also derive protection from any prickle-rich, type- $\underline{1}$ and type- $\underline{2}$ stems situated nearby.

Comparison with previous findings.- In contrast to present observations, previous investigators of $S$. auriculata reported maximal prickle lengths of 4 mm (Bullard \& Allen 2013; Coker 1944; Holmes 2002). Apparently, the earlier reports of "dark" and black-tipped prickles, by Coker (1944) and Proenza and Andreu (2013), respectively, were of aged specimens.

\section{CONCLUSIONS}

Current findings, additional unreported personal observations, and the references presently cited indicate, collectively, that $S$. auriculata is a highly variable species. Clumps, thereof, may differ from each other in overall size; in aspects of their underground stems; in the range of sizes and shapes of, and in the presence vs. 
absence of mottling of, their foliage leaves; and, apparently, in the maximum density and size of their prickles. Clearly, present observations reflect just part of, and certain atypical manifestations of, that variation.

\section{ACKNOWLEDGMENTS}

I express deep appreciation to Donna McGinnis (the Director of the Naples Botanical Garden [NBG]) and to NBG for providing laboratory space for the present study and for housing the SWF Herbarium. Too, I thank these additional staff members/associates of NBG for their diverse contributions: Karin Balsbaugh, Gary Boivin, Brian Bovard, Kristen Camisa, LaVon Coate, James Connally, Gavin Cooke, Jessica DeYoung, Mary Dominguez, Eric Foht, Marissa Hale, Anne Li, Stuart Nayer, Kim Olson, Barbara Pace, Amanda Packard, Karen Pattison, Karen Relish, Jean Roche, Ben Schoenberg, Dede Schoenberg, Marco Stavole, Renee Waller, Chad Washburn, Eileen Watkins, Julia Wilkinson, and Annette Winkler. I extend especial gratitude to Matt Vance and Bill Parken of FFWCC for making possible, and for assisting me in diverse ways during, current research. I likewise express deep thanks to Jean McCollom, Brenda Thomas, and Rebecca Wilder. Too, I thank Walter Judd and Kenneth Cameron for reviewing the manuscript of this paper and for comments that were extremely helpful and most appreciated.

\section{REFERENCES}

Arber, A. 1920. Tendrils of Smilax. Bot. Gaz. 69(5):438-442.

Arber, A. 1925. Monocotyledons: A morphological study. Cambridge University Press, London, England.

ARBER, A. 1950. The natural philosophy of plant form. Cambridge University Press, London, England.

Bullard, A.J. \& C.M. Allen. 2013. Synopsis of the woody species of Smilax in the eastern United States north of peninsular Florida. J. North Carolina Acad. Sci. 129(2):37-43.

CAPonetti, J.D. \& M.W. Quimby. 1956. The comparative anatomy of certain species of Smilax. J. Amer. Pharm. Assoc. 45(1):691-696.

Clewell, A.F. 1985. Guide to the vascular plants of the Florida Panhandle. University Presses of Florida/Florida State University Press, Tallahassee, Florida, U.S.A.

COKER, W.C. 1944. The woody Smilaxes of the United States. J. Elisha Mitchell Sci. Soc. 60:27-69 plus Plates 9-39.

CorrelL, D.S. \& H.B. Correll. 1982. Flora of the Bahama Archipelago. A.R. Gantner Verlag KG., Vaduz, Germany.

DunCAN, W.H. 1975. Woody vines of the southeastern United States. The University of Georgia Press, Athens, Georgia, U.S.A.

FISHER, J.B. \& J.C. FRENCH. 1976. The occurrence of intercalary and uninterrupted meristems in the internodes of tropical monocotyledons. Amer. J. Bot. 63(5):510-525.

Godfrey, R.K. 1988. Trees, shrubs, and woody vines of northern Florida and adjacent Georgia and Alabama. The University of Georgia Press, Athens, Georgia, U.S.A.

Godfrey, R.K. \& J.W. Wooten. 1979. Aquatic and wetland plants of southeastern United States. Monocotyledons. The University of Georgia Press, Athens, Georgia, U.S.A.

Hallé, F., R.A.A. Oldeman, \& P.B. Tomlinson. 1978. Tropical trees and forests: An architectural analysis. Springer-Verlag, Berlin, Germany

Holmes, W.C. Smilacaceae Ventenat. 2002. In: Flora of North America Editorial Committee, eds. Flora of North America north of Mexico. Vol. 26. Oxford University Press, New York, U.S.A.

JudD, W.S. 1998. The Smilacaceae in the southeastern United States. Harvard Pap. Bot. 3(2):147-169.

LoNG, R.W. \& O. LAKELA. 1971. A flora of tropical Florida. University of Miami Press, Miami, Florida, U.S.A.

Martin, B.F. 1975. Developmental studies in Smilax. PhD dissertation. Louisiana State University, Baton Rouge, Louisiana, U.S.A.

MARTIN, B.F. \& S.C. TUCKER. 1985. Developmental studies in Smilax (Liliaceae). I. Organography and the shoot apex. Amer. J. Bot. 72:66-74.

Morong, T. 1894. The Smilaceae of North and Central America. Bull. Torrey Bot. Club 21(10):419-443.

Nelson, G. 1996. The shrubs and woody vines of Florida. Pineapple Press, Inc., Sarasota, Florida, U.S.A.

Proenza, L. \& M. Andreu. 2013. Key to nine common Smilax species of Florida. FOR307. School of Forest Resources and Conservation, UF/IFAS Extension, Gainesville, Florida, U.S.A. 
Qı, Z., K.M. Cameron, P. Lı, Y. Zhao, S. Chen, G. Chen, \& C. Fu. 2013. Phylogenetics, character evolution, and distribution patterns of the greenbriers, Smilacaceae (Liliales), a near-cosmopolitan family of monocots. Bot. J. Linnean Soc. 173:535-548.

Radford, A.E., H.E. Ahles, \& C.R. Bell. 1968. Manual of the vascular flora of the Carolinas. The University of North Carolina Press, Chapel Hill, North Carolina, U.S.A.

SMALL, J.K. 1933. Manual of the southeastern flora. University of North Carolina Press, Chapel Hill, North Carolina, U.S.A.

TroLl, W. 1937. Vergleichende Morphologie der höheren Pflanzen. Vol. 1, Parts 1-3. Gebrüder Borntraeger, Berlin, Germany.

WALTER, T. 1788. Flora Caroliniana. Printed for J. Wenman Publisher, London, England.

WILDER, G.J. 1976. Structure and development of leaves in Carludovica palmata (Cyclanthaceae) with reference to other Cyclanthaceae and Palmae. Amer. J. Bot. 63(9):1237-1256.

WILDER, G.J. 1977a. Structure and symmetry of species of the Asplundia group (Cyclanthaceae) having monopodial vegetative axes: Schultesiophytum chorianthum, Dicranopygium sp. nov., Asplundia rigida, and Thoracocarpus bissectus. Bot. Gaz. 138(1):80-101.

WILDER, G.J. 1977b. Structure and symmetry of species of the Asplundia group (Cyclanthaceae) having sympodial vegetative axes: Evodianthus funifer and Carludovica palmata. Bot. Gaz. 138(2):219-235.

WILDER, G.J. 1981a. Structure and development of Cyclanthus bipartitus Poit. (Cyclanthaceae) with reference to other Cyclanthaceae. I. Rhizome, inflorescence, root, and symmetry. Bot. Gaz. 142(1):96-114.

WILDER, G.J. 1981b. Structure and development of Cyclanthus bipartitus Poit. (Cyclanthaceae) with reference to other Cyclanthaceae. II. Adult leaf. Bot. Gaz. 142(2):222-236.

Wilder, G.J., J.M. Mccollom, \& N.J. Bissett. 2019. A floristic inventory of the Holmes Avenue Tract (Highlands Co.), Florida. J. Bot. Res. Inst. Texas 13(2):499-543

WunderLin, R.P. \& B.F. HANSEN. 2011. Guide to the vascular plants of Florida, $3^{\text {rd }}$ ed. University Press of Florida, Gainesville, Florida, U.S.A.

YATES, I.E. \&W.H. DunCAN. 1970. Comparative studies of Smilax, section Smilax, of the southeastern United States. Rhodora 72(791):289-312. 